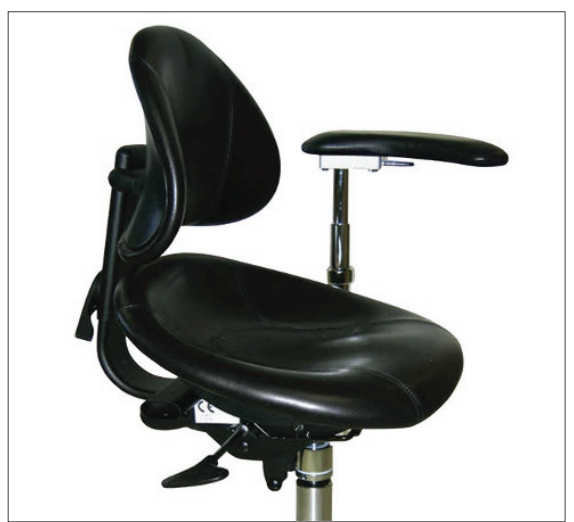

\section{ABILITY TO MOVE FREELY}

Support Chairs' Support Stools have been developed for professionals working in sedentary positions, where both body support and the ability to move freely are essential.

The seat and back of the Support Stool is designed to take the weight off the back and provide maximum comfort; the fully adjustable back support and bowl-shaped seat ensuring a proper posture.

Each seat is manufactured to order so that they meet all the user's needs including specific requirements on colours and materials. Support Chairs also offer a wide range of accessories so that the stool can be customised to the operator's specific needs.

These include foot rings, which can take the weight off the legs when working in a high position; a foot activator, which allows height adjustment using only the feet; Relax Armrests, which allow the arm to move freely in the horizontal plane; and Hydro Armrests, which allow the arm to move freely in both the horizontal and vertical planes. Support Stools are now also available with a new Swing and Swing Mini Armrest.

Reader response number 61

\title{
EXPRESS YOUR OWN UNIQUE STYLE
}

Genus is not tied to any particular manufacturer and can therefore source and supply the right furniture, fixtures, fittings and equipment that you need. Genus also oversees the construction phase in order to deliver the project on time and to budget, and providing a central, reliable point of contact.

To achieve an expression of your own unique style though your surroundings and equipment, Genus uses CAD and 3D software to aid visualisation of the layout and equipping of the

practice as a whole and to allow refinement down to the smallest detail.

Whether you are looking to refurbish or to make the move and commit to a brand new practice, or whatever your design and build needs, Genus is dedicated to meeting them.

Genus appoints a specialist to oversee the project who is always on hand as a point of contact, allowing the dentist to spend more of their valuable time treating patients.

Reader response number 62

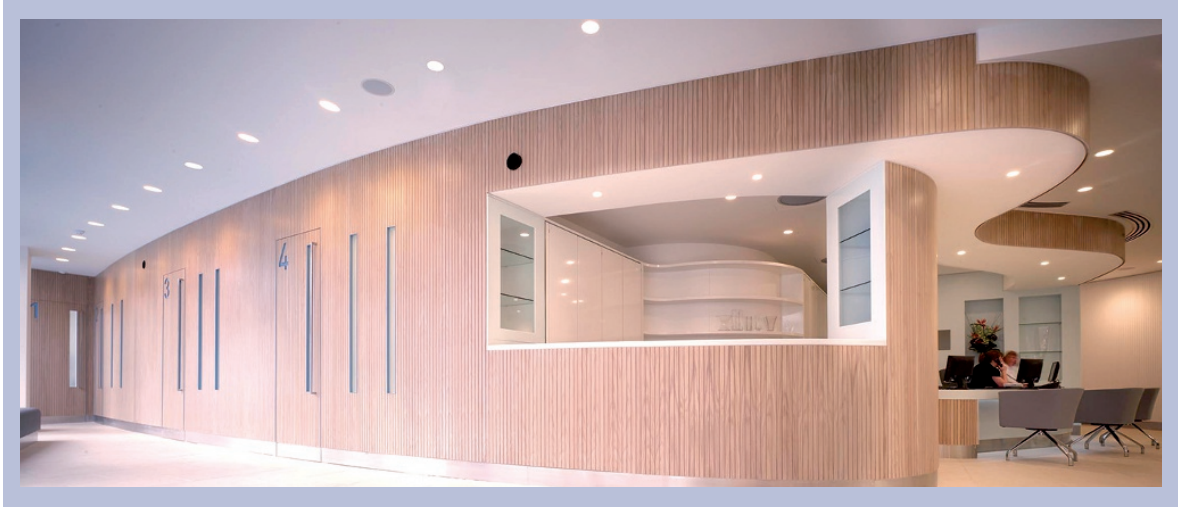

\section{NEW ENDODONTIC COURSE LAUNCHED AT WARWICK}

Warwick Dentistry, based at the University of Warwick, has launched a new MSc in Endodontics for general dental practitioners. The first cohort of students has already begun the course, which combines seminar-style teaching with hands-on experience.

The new MSc covers topics including evidence-based dentistry, online literature research, tooth anatomy, endodontic educational tools, use of surgical microscopes and digital photography.

Students can also experience a different technology for mechanical root canal shaping and the 'Thermafill' root canal obturation technique. The programme is delivered by leading professionals, academics and researchers in the field of endodontic dentistry, and supported by respected academics from the field of continuing professional development.

Reader response number 63

\section{BLENDED LEARNING}

The blended learning team at the King's College London Dental Institute has announced that its latest Flexible Graduate programme, an MSc in Aesthetic Dentistry, is now available for students to study.

The course has been designed for busy dentists who wish to learn new and advanced techniques while continuing to work in their practice in any country in the world. It is the daughter of the highly popular MClinDent (Fixed and Removable Prosthodontics), now in its 11th year.

The course takes a blended learning approach, with an annual residential course in London and course materials and twice monthly online support from tutors (including access to videos showing dental techniques, and e-library resources).

The face to face courses are nine days in duration and cover the necessary practical training, taught by a panel of experts from the King's College London faculty and leading international experts in the field.

Examples of topics include composite restorations for aesthetic and wear cases, simple gingival and osseous procedures through to managing the occlusion and implant aesthetics. The courses are 9 days in duration. Reader response number 64 